\title{
RECALLED TREATMENT BY PARENTS AMONG COLLEGE MALES AND BLOOD PRESSURE- LEVELS VS. VARIABILITY*
}

\author{
Ernest Harburg, $\uparrow$ Noel F McGinn and James B Wigle
}

(Recelved 21 May 1965)

A REVIEW of research relating high blood pressure and physiological characteristics indicates that the high blood pressure patient is described as anxious, sensitive, inwardly hostile, but submissive in social situations [1] This particular syndrome of personality characteristics has led some clinicians and researchers to conclude that (1) high blood pressure patients suffered from threatening parents in their youth and

(2) that the constant stress engendered by their parents acted to elevate blood pressure to persistently high levels For example, according to Malmo

continuous overarousal such as that experienced in a threatening environment

in childhood may result in impairment of central inhibitory mechanısms

that control physiological activity levels

However a review of the literature has revealed only a few studies [3-5] which relate characteristics of parents to the blood pressure of patients in treatment Saul [3] reported his seven patients in psychoanalysis to have had domıneering mothers, but he did not employ a control group Wolf et al [4] who did, found their hypertensives to have had domineering mothers who were intolerant of displays of anger Another study, Harris et al [6] involved normal adolescents as subjects The only parent variable distınguishıng high and low blood pressure subjects was that the former had upwardly mobile fathers

Given the relative importance of the parent-treatment-leads-to-high-blood-pressure hypothesis, for both prevention of, and therapy for, high blood pressure, the present study was designed to more adequately investigate the suspected relationships This study is based on the general assumption that excessive stress in parent-child relationships acts to damage inhibitory mechanısms and/or induce "neurotic" behavior in children which in turn facilitates the development of high blood pressure levels or variability in blood pressure Specifically, we assume that parental treatment which induces excessive anger and fear or grief from being unloved and/or excessively punished, may condition the young organism to over-react emotionally to cues of stress The resultant contınuous arousal of emotion and anxiety may make certain

* This research was supported by Grant No H 2578 of the United States Department of Health, Education and Welfare to Sibley W Hoobler, M D, Hypertension Clinic, University of Michigan Hospital Facilities at the University of Michigan Health Service were graciously provided by Morley Beckett, M D To Stevo Julius, M D , the research physician who collected the medical data, we owe a special debt of gratitude

$\dagger$ Assistant Professor of Psychology in Nursing, School of Nursing, University of Michigan, Ann Arbor, Michigan 
organsms prone to increased blood pressure levels and/or to increased variability of pressure For the purpose of the research it was hypothesized that subjects who report their parents as punitive, irritable, unloving and inconsistent would have higher or more variable blood pressure than those who recalled their parents in a more favorable light Further, since social mobility has been associated with authoritarian attitudes [7] and has already been related to high blood pressure on adolescents, it was expected that subjects who saw their fathers as concerned with mobility would have higher or more variable blood pressure Finally, because sex role identification problems play a part in enduring personal conflicts, it was expected that subjects whose mother was dominant over the father would be more prone to higher or more variable blood pressuie $[8,9]$

\section{Subjects}

\section{METHODS}

The 83 white, male subjects for this study consisted of incoming students registering for their first semester at the University of Michigan in September 1961 A single blood pressure reading was taken by one of five trained examiners from roughly every third student (sitting position) who were members of a line moving through the mass procedures of a physical examination Out of about 800 students whose blood pressure was determıned by standard techniques, 50 subjects were selected because their systolıc blood pressures exceeded $139 \mathrm{~mm} \mathrm{Hg}$, and 50 because theır diastolic pressure was less than $110 \mathrm{~mm} \mathrm{Hg}$ There were no differences in diastolic levels between the two groups of the 100 subjects thus selected, 83 completed all phases of the study as paid volunteers When these 83 subjects were given a second casual blood pressure reading several weeks later, the once "bimodal" distr1butıon of systolic levels became normalızed due to a predictable regression towards the mean as found by others, e g Thacker [10] Nevertheless we also expected that enough individuals would maintain these extremes of normal ranges to allow the maximal distribution of blood pressure to serve in analysis About 33 per cent of the 83 subjects did remain over $140 \mathrm{~mm} \mathrm{Hg}$ at their second reading, 25 per cent remained below $100 \mathrm{~mm} \mathrm{Hg}$ and 42 per cent changed toward the normal range

The average age of the total group of 83 subjects was 213 years, 77 per cent were between the ages of 17 and 25 Ninety-three per cent were from homes where the parents had never been separated or divorced and were still living together

\section{Recall of parent-child relations}

Two weeks after selection and, in all cases, before being tested by the research physician, subjects were administered a Family Questionnaire given during a single test session This form had two parts and was devised by one of the authors [11] The first part elicited background information and responses to a series of Likert-scaled items about subjects' parents when subject was a child Being a child was defined as from earliest memories untıl about fourteen years old The items included for analysis in this report are frequency of physical punishment by father and mother, amount of affection demonstrated toward the son by each parent, the son's view of the dominance of the father or mother in the family when he was a child, ${ }^{*}$ and the amount of time the father spent with his son

The second part of this form consisted of the Parent Image Differential which has been described in detail elsewhere $[11,12]$ and is therefore briefly described here This form is an adaptation of the semantic differentral technıque devised by Osgood, Sucı and Tannenbaum [13] The subject is asked

* The punishment items were (1) How frequently did (parent) punish you physically? (6 point scale) (2) How hard were you ever hit " (regardless of how often) (6 point scale) The demonstration of affection item was How often did your parents show affection to you when you were a child? (6 point scale) The index of domunance was the sum of responses to these questions (1) Which parent would you say was actually the head of the family when you were a child? (2) If your father wanted your mother to do something that she really didn't want to do, what is your estimate of the chance that she would do it? (3) If your mother wanted your father to do something that he really didn't want to do, what is your estimate of the chance that he would do it? (4) Which parent would you estımate as usually having the final word in decisions concerning the family, when you were a child? (5) (If parents disagreed about family matters) Which parent usually got his or her way in the final decision? 
to read a concept at the top of the page, and rate its meaning on a number of scales below the concept on the page The six concepts used in this study were

How my father treated me when I was a child

How my mother treated me when I was a child

How my father taught me when I was a child

How my mother taught me when I was a child

How my father disciplined me when I was a child

How my mother disciplined me when I was a child

A sample of the fifteen scales included below each concept is

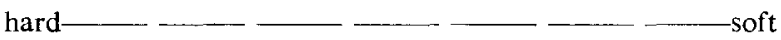

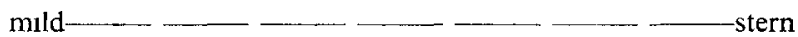

It should be mentioned that in this study cooperation from subjects was such that there was almost no missing data on any item in the whole questionnarre

The scale responses for all 83 subjects to each of the concepts were factor analyzed by varımax rotation, and yielded a set of 12 factors in all, each factor pertaining to a given concept Those scales with factor loadings of 040 or more and not loaded higher on any other factors were selected as being salıent The factor score for each individual was computed by simply addıng these salient scale scores for the given items Most of the factor scores were normally distributed, as were the individual scales, but some, like "warm-cold" with the concept How my (parent) treated me, were skewed toward the socially desirable endpoint, $1 \mathrm{e}$ "warm" Nevertheless, recent evidence from a group of college females, selected for high and low acquiescence response sets, indicates that neither of the major "affection" or "severity" factors in the Parent Image Differential was significantly correlated with standard measures of either acquescence response set or "social desirability" set "

In the following description of the factors, the awkwardness of language compels the use of extreme adjectives which mark the ends of the scales Actually each factor score is a continuous, normally distributed variable, subject to the skewness of certain contents such as Affection These endpoint adjectives simply give the direction of Pearsontan correlations which were used in this analysis to facilitate use of a multiple regression computer program

Disregarding concept, the factors for Father were

(1) Potency-Father was described as "stern," "hard" and "severe", or "mild," "soft" and "lenıent" This factor essentrally gives a degree-of-severity index

(2) Support-This described a relationshıp between father and son which varied along a dimension of warm and skilfful encouragement Salient scales were "consistent-inconsistent" and "skıllfulawkward"

(3) Inclusion-This described the extent to which father and son were jointly involved in activities, e $g$ "rarely did things together with me-often did things together with me"

(4) Irritability-This was defined by such scales as "easy to irritate hım-hard to irritate him," and "impatient with me-patient with me"

(5) Intropunitiveness--Subject described his reaction to discipline as blaming himself, or as blaming Father, feeling guilty or feeling resentment

(6) Demand style-This was so labeled because the salient scales suggested a continuum of rationality-irrationality in Father's demands for behavioral conformity, e g "usually ordered me-usually persuaded me"

The Potency, Irritability and Intropunitiveness factors for Mother contained almost identical scales as those for Father, but only the Intropunitıveness factors for Father and Mother were significantly correlated $(r=040)$ The other factors for Mother were

(1) Affection-This was close to the Father Support factor, but the security of the environment provided by Mother seemed based on love while that given by Father was based upon the consistency of his behavior However, Mother Affection was significantly $(r=033)$ related to Father Support

(2) Justice-This was the consistency dimension on the Father Support factor, and was just significantly $(r=021)$ related to that factor Its defining scales were "just-unjust" and "Inconsistentconsistent"

* Our thanks to R Quinn for permission to use part of his thesis research Conformity, personality, and the extraneous third variable-acquiescence response set Unpublished doctoral dissertation University of Michigan (1963) 
(3) Tolerance-This factor represented the degree to which subject reported his mother as allowing or encouraging independent behavior It had no clear equivalent among the Father factors

Reliability and Validity of the Parent Image Differential The concurrent validity of the Parent Image factors is shown by their correlations with the questionnaire items The Father Potency factor score was correlated with the answers to the item about the frequency of Father's punishment $(r=052)$ but not to the frequency of Mother's punishment, nor to ratings of father's affection or mother's affection The same result holds for the Mother Potency factor Similarly, the Father Support factor was correlated with the question about Father's affection $(t=052)$ but not with Mother's affection, the same result holds for the Mother Affection factor

Test-retest reliability was measured when 26 of the subjects took four of the Parent Image Differential Concepts twice For 24 of these subjects the second administration occurred more than 11 months after the first, for the other two the administrations were six months apart Factor scores for the two administrations were computed and correlated to yield test-retest reliability coefficients These reliabilities are presented in Table 1 Only one of the coefficients was below 050 , the median tor the others was about 070 In an as yet unpublished report [14] it has been found that successive

TABLE 1 -Test-Retest Reliabilities FOR PARENT IMAGE FACTORS AFTER 11 MONTH INTERVAL $(N=26)$

\begin{tabular}{lc}
\hline Parent Image Factors & $R$ \\
\hline Father & \\
Potency & 065 \\
Support & 077 \\
Intropunitiveness & 076 \\
Demand style & 052 \\
Mother & \\
Potency & 077 \\
Affection & 064 \\
Justice & 079 \\
Irritability & 048 \\
Intropunitiveness & 066 \\
\hline
\end{tabular}

Three of the twelve factors are not presented as data, for only two concepts were collected All Pearsonian correlations equal to or greater than 050 are significant beyond the 001 level, $d f=24$

samples from populations of male (and female) college students and a Mexican group of males, controlled on social class, produced significantly similar Parent Image factor structures, testing with the Kaiser Factor Similarity Program [15] In another study the same scales were used by both of the parents of 83 of the subjects to describe Hou I believe I (treated/disciplined) my son when he was a child here again significantly simılar structures emerged from each parent's report and their son's report

Because the Parent Image Differential purports to measure perceptions which subjects had of their parents during childhood, and because there is no independent way to measure perceptual content other than self-report, it is impossible to directly support the validity of the instrument However, if it is possible to demonstrate that the perceptions measured are relatively stable, one can argue that the perceptions originated in childhood and are therefore "valıd" for the purposes of this research The reliability data presented above support thıs conclusion

\section{PROCEDURES}

The Parent Image semantic and the Family Questionnaire were admınıstered as part of a battery of tests in a group testing situation about two weeks before $S$ had his physical examination for the study The average administration time for the two forms was about $35 \mathrm{~min}$

On arriving at the research physician's laboratory for his examination, $S$ 's second casual blood pressure was read in the sitting position, as it was for the first casual measure taken on the registration line The average of these two measures is the Average Casual blood pressure The absolute difference between these two casual readings taken under two different (slightly stressful) conditions is called Casual Variability The $S$ then reclined in a hospital bed, unclothed but under sheets for $20 \mathrm{~min}$ Blood pressure readings were taken every five minutes during this period and at the end of 20 min, three readings were taken one minute apart The $S$ was then given a Cold Pressor test and a 
$\checkmark$ alsalva test, for another part of the gencral rescarch Results of the Cold Pressor reactivity test are more fully reported elsewhere [16] Then a method for self-determination of blood pressure was explained to $S[17]$ Subjects were instructed to take readings at home in the sitting position, before breakfast, dinner and before retırmng at night, over two consecutive days The median of these six readings is referred to as Median Home blood pressure Finally the mean of three readings taken after 20 minutes of bed rest, and the Median Home blood pressure level were averaged to produce an index of usual blood pressure level Of the initial $100 \mathrm{Ss}, 83$ completed the psychological examination and the casual blood pressure measures, and $74 S \mathrm{~s}$ completed the home blood pressure measures The means of these measures and their intercorrelations are presented in Table 2 The highest correlations were between the measures of blood pressure levels, correlations between levels and vantability were slight

TABLe 2 - MEANS AND intercorrelations of AVERAGE CASUAL, USUAL, AND CASUAL VARIABILITY BLOOD PRESSURE MEASURES $(N=74)$

\begin{tabular}{|c|c|c|c|c|c|c|c|}
\hline \multirow{2}{*}{ Blood pressure measure } & \multirow{2}{*}{ Mean } & \multirow{2}{*}{ SD } & \multicolumn{3}{|c|}{ Systolic } & \multicolumn{2}{|c|}{ Didstolic } \\
\hline & & & $\begin{array}{l}\text { Average } \\
\text { casual }\end{array}$ & Usual & $\begin{array}{l}\text { Casual } \\
\text { varia- } \\
\text { bulity }\end{array}$ & $\begin{array}{c}\text { Average } \\
\text { casual }\end{array}$ & Usual \\
\hline \multicolumn{8}{|l|}{ Systolic } \\
\hline $\begin{array}{l}\text { Average casual } \\
\text { Usual } \\
\text { Casual variabılity }\end{array}$ & $\begin{array}{r}1252 \\
1236 \\
163\end{array}$ & $\begin{array}{l}189 \\
116 \\
115\end{array}$ & $\begin{array}{l}083 \dagger \\
016\end{array}$ & 016 & & & \\
\hline \multicolumn{8}{|l|}{ Diastolic } \\
\hline $\begin{array}{l}\text { Average casual } \\
\text { Usual } \\
\text { Casual varability }\end{array}$ & $\begin{array}{l}682 \\
661 \\
137\end{array}$ & $\begin{array}{r}116 \\
89 \\
95\end{array}$ & $\begin{array}{l}038 \dagger \\
012 \\
028^{*}\end{array}$ & 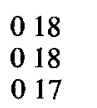 & $\begin{array}{r}-011 \\
007 \\
-005\end{array}$ & $\begin{array}{r}035 \dagger \\
-009\end{array}$ & -007 \\
\hline
\end{tabular}

$* p$ less than 005

$T p$ less than 001

I he program used for the analysis of data on this study is a stepwise regression procedure which selects one independent variable at a time and enters it into the regression equation The selection of the particular independent variable is based on the amount of increase which it causes in the multiple correlation This program (developed by F W Westervelt at The University of Michigan Computıng Center) requires the user to specify a minimum $F$ level for an independent variable to be entered in the equation For the purposes of this study, the $F$ level was set at 000 in order that all 26 independent variables would have a chance to be used We are reporting independent variables in the order of therr appearance in the equation, but only up to the point where no further varrables contributed less than the 010 level $\ddagger$

\section{Blood pressure levels}

\section{RESULTS}

Table 3 presents the simple correlations between the Parent Image semantic factor scores and Average Casual blood pressure levels There is one significant correlation Subjects with high systolic Average Casual blood pressure tended to describe their fathers as mild, soft and lenient However, it should be noted that, by chance, one would expect a significant correlation among a group of 24 We cannot, therefore, assume that the obtained correlation represents a meaningful association

Table 3 also presents the correlations for Usual Blood Pressure Again, there is only one correlation that attains significance Subjects with high systolic Usual Blood Pressure tended to describe their mother as hard to irritate

Table 4 presents the correlations between the Family Questionnaire items and the two blood pressure measures There are no significant correlations between the Family Questionnaire items and Average Casual Blood Pressure There are two with Usual Blood Pressure Subjects with high systolic Usual Blood Pressure tended to report that their father applied mild physical punishment, subjects with high diastolic Usual Blood Pressure tended to report that their father seldom punished physically All three of these correlations are in a direction opposite to those hypothesized Indeed, of the 16 correlations between blood pressure levels and treatment by father, the signs of 14 are in the direction opposite to those hypothesized That is, the data suggests that the higher the blood pressure level, the more socially stable and less punitive the father is recalled

c Our thanks to Lindsey Crooks for her help in the statistical analysis 
Table 3 -Correlations of average Casual blood pressure level $(N=83)$ and usual blood PRESSURE LEVEL $(N=74)$ WITH PARENT IMAGE FACTORS

\begin{tabular}{|c|c|c|c|c|}
\hline \multirow{2}{*}{$\begin{array}{c}\text { Parent Image Factors } \\
\text { (higher degree }=\text { higher score) }\end{array}$} & \multicolumn{2}{|c|}{ Average casual blood pressure } & \multicolumn{2}{|c|}{ Usual blood pressure } \\
\hline & Systolic & Diastolic & Systolic & Diastolıc \\
\hline \multicolumn{5}{|l|}{ Father } \\
\hline Potency (severity) & $-023^{*}$ & -015 & -018 & -006 \\
\hline Support & -007 & -001 & -005 & -016 \\
\hline Inclusion & -018 & -008 & -015 & -011 \\
\hline Irritabılity & -004 & 006 & -003 & -011 \\
\hline Intropunitiveness & -001 & -003 & -004 & -018 \\
\hline Demand style (explains) & 002 & 006 & 005 & 004 \\
\hline \multicolumn{5}{|l|}{ Mother } \\
\hline Potency & -010 & -013 & -014 & -012 \\
\hline Affection & 006 & -010 & 008 & 012 \\
\hline Justice & 011 & 008 & 005 & 000 \\
\hline Tolerance for undependence & 001 & -008 & 003 & 002 \\
\hline Irritability & -016 & -003 & $-022 *$ & -004 \\
\hline Intropunitiveness & 011 & -004 & 008 & 006 \\
\hline
\end{tabular}

* $p$ less than 005

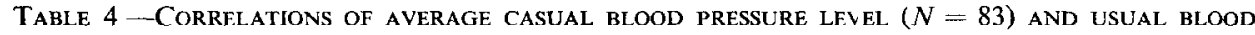
PRESSURE LEVEL $(N=74)$ WITH FAMILY QUESTIONNAIRE ITEMS

\begin{tabular}{|c|c|c|c|c|}
\hline \multirow{2}{*}{$\begin{array}{l}\text { Family Questionnaire Items } \\
\text { (higher degree = higher score) }\end{array}$} & \multicolumn{2}{|c|}{$\begin{array}{l}\text { Average casual } \\
\text { blood pressurc }\end{array}$} & \multicolumn{2}{|c|}{ Usual blood pressure } \\
\hline & Systolic & Diastolic & Systolic & Diastolic \\
\hline \multicolumn{5}{|l|}{ Father } \\
\hline $\begin{array}{l}\text { Frequency physical punishment } \\
\text { Intensity physical punishment } \\
\text { Amount affection demonstrated } \\
\text { Concern with mobility }\end{array}$ & 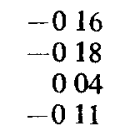 & $\begin{array}{ll}-0 & 12 \\
-0 & 08 \\
-0 & 10 \\
-0 & 05\end{array}$ & $\begin{array}{rl}-0 & 19 \\
-0 & 26^{*} \\
0 & 15 \\
0 & 05\end{array}$ & $\begin{array}{l}-024 \dagger \\
-008 \\
-020 \\
-008\end{array}$ \\
\hline \multicolumn{5}{|l|}{ Mother } \\
\hline $\begin{array}{l}\text { Frequency physical punıshment } \\
\text { Intensity physical punishment } \\
\text { Amount affection demonstrated }\end{array}$ & 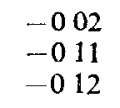 & 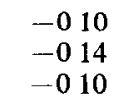 & $\begin{array}{r}-013 \\
-016 \\
003\end{array}$ & 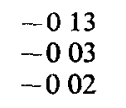 \\
\hline \multicolumn{5}{|l|}{ Joint } \\
\hline $\begin{array}{l}\text { Frequency parent disagreement } \\
\text { Dominant parent (hıgh }=\text { mother) } \\
\text { Change in social class }\end{array}$ & $\begin{array}{r}-005 \\
002 \\
-006\end{array}$ & $\begin{array}{r}003 \\
003 \\
-008\end{array}$ & $\begin{array}{r}-006 \\
007 \\
016\end{array}$ & $\begin{array}{r}-008 \\
007 \\
-017\end{array}$ \\
\hline
\end{tabular}

$1 p$ less than 005

Tables 5 and 6 present those Parent Image factors and Family Questionnarre variables (out of a total of 26 used) which loaded in a multiple correlation equation predicting to each of the blood pressure variables In the tables the independent variables are presented in the order in which they entered the equation

In Table 5 we see that $S$ s with high systolic Average Casual readings were those who reported that their father was mild, soft and lenient but who rarely did things together with them, and whose mother was hard to irritate As there were no independent variables which had a significant correlation with diastolic Average Casual Blood Pressure, no multıple correlation emerged

In Table 6 it is shown that $S \mathrm{~s}$ with high systolic Usual blood pressure were those who reported mild physical punishment received from father, mother hard to irritate, father rarely did things together with $S$, but father frequently demonstrated affection Subjects with high diastolic Usual blood pressure were those who reported that father seldom punished physically but seldom showed affection 
TABLE 5 -Multiple CORRELATION $(R)$ USING PARENT IMAGE SEMANTIC FACTORS AND FAMILY QUESTIONNAIRE ITEMS AS INDEPENDENT VARIABLES AND AVERAGE CASUAL BLOOD PRESSURE AS THE DEPENDENT VARIABLE $(N=83)$

\begin{tabular}{lllll}
$\quad$ Average casual blood pressure & $R$ & $\begin{array}{c}F- \\
\text { level }\end{array}$ & $d f$ & $P^{*}$ \\
\hline $\begin{array}{l}\text { Systolic } \\
\text { Father potency (mild) }\end{array}$ & 023 & 442 & 79 & $<005$ \\
$\quad \begin{array}{l}\text { Father inclusion (rarely did things together } \\
\quad \text { with me) }\end{array}$ & 030 & 318 & 78 & $<010$ \\
$\quad \begin{array}{l}\text { Mother irritability (hard to irritate her) } \\
\text { Diastolic }\end{array}$ & $035 \dagger$ & $\mathbf{3 1 0}$ & 77 & $<010$ \\
$\quad$ (no multiple relations) & & & &
\end{tabular}

* The $p$ value shown in this and other tables represents the level of significance at which the particular variable entered the prediction equation

$\dagger$ The $p$ value for this $R$ is less than 005

TABle 6 -Multiple Correlation $(R)$ using Parent IMAGe SEMANTIC Factors AND FAMILY QUESTIONNAIRE ITEMS AS INDEPENDENT VARIABLES AND USUAL BLOOD PRESSURE AS THE DEPENDENT VARIABLE $(N=74)$

\begin{tabular}{|c|c|c|c|c|}
\hline Usual blood pressure & $R$ & $\underset{\text { level }}{F-}$ & $d f$ & $P$ \\
\hline \multicolumn{5}{|l|}{ Systolic } \\
\hline $\begin{array}{l}\text { Father intensity punıshment (mild) } \\
\text { Mother irritability (hard to irritate her) }\end{array}$ & $\begin{array}{l}026 \\
036\end{array}$ & $\begin{array}{l}483 \\
472\end{array}$ & $\begin{array}{l}67 \\
66\end{array}$ & $\begin{array}{l}<005 \\
<005\end{array}$ \\
\hline $\begin{array}{l}\text { Father inclusion (rarely did things together } \\
\text { with me) } \\
\text { Father demonstration of affection (frequent) }\end{array}$ & $\begin{array}{l}039 \\
0441\end{array}$ & $\begin{array}{l}218 \\
366\end{array}$ & $\begin{array}{l}65 \\
64\end{array}$ & $\begin{array}{l}<015^{*} \\
<010\end{array}$ \\
\hline \multicolumn{5}{|l|}{ Diastolic } \\
\hline $\begin{array}{l}\text { Father frequency punishment (seldom punished } \\
\text { physically) } \\
\text { Father demonstration of affection (seldom } \\
\text { showed affection) }\end{array}$ & 024 & 419 & 67 & $\begin{array}{l}<005 \\
<010\end{array}$ \\
\hline
\end{tabular}

* It happens occasionally that the $F$-level will decrease until it is no longer significant and then will jump back to a much higher level This indicates that at a certain point, no variable entered by itself into the equation is significant but that the same variable in conjunction with others may make a significant contribution

$\uparrow p$ less than 001

$\ddagger p$ less than 005

\section{Blood pressure vartability}

This study also examined the relationships of parent treatment and blood pressure variability on the assumption that the assumed "neurotic" or inhibitory mechanisms may be less related to levels of blood pressure than to measures of variability

The findings in Table 7 show that Systolic Casual Variability is best predicted by a combination of two variables which taken alone had significant zero-order correlations with it Subjects who reported that punishment administered by their father was not too frequent and who perceived an increase in the social status of their family tend to be those who had large discrepancies between two Systolic Casual blood pressure readings The equation accounts for about nine per cent of the variance of Systolic Casual Variability scores 


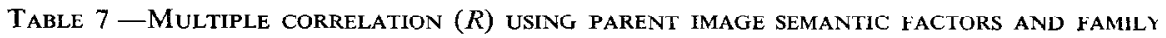
QUESTIONNAIRE ITEMS AS THE INDEPENDENT VARIABLES AND CASUAL VARIABILITY AS THE DLPENDENT VARIABLE $(N=83)$

\begin{tabular}{|c|c|c|c|c|}
\hline Casual variability & $R$ & $\begin{array}{c}F- \\
\text { level }\end{array}$ & $d f$ & $p$ \\
\hline \multicolumn{5}{|l|}{ Systolic } \\
\hline Change in social class (up) & 023 & 459 & 79 & .005 \\
\hline Father frequency of punishment (high) & $031 *$ & 359 & 78 & -010 \\
\hline \multicolumn{5}{|l|}{ Diastolic } \\
\hline $\begin{array}{l}\text { Mother tolerance for independence (disagreeing } \\
\text { with her was encouraged) }\end{array}$ & 025 & 544 & 79 & 0025 \\
\hline Father support (awkward, inconsistent) & 035 & 564 & 78 & 0025 \\
\hline Father dominant & 042 & 467 & 77 & 005 \\
\hline Father irritability (suppressor variable) & 044 & 228 & 76 & $\therefore 015$ \\
\hline Father time with children (less time) & 047 & 266 & 75 & 015 \\
\hline $\begin{array}{l}\text { Father intropunitiveness (made me feel } \\
\text { resentment) }\end{array}$ & 051 & 336 & 74 & -010 \\
\hline Mother affection (suppressor variable) & 053 , & 281 & 73 & 010 \\
\hline
\end{tabular}

$* p$ less than 005

t $p$ less than 001

Diastolic Casual Varıability is best predicted by a combindtion of seven independent variables These are Mother Tolerance for Independence, Father Support, Father dominant in the family, Father Irritability, Father time with children, Father Intropunitiveness and Mother Affection Subjects with large discrepancies in two consecutive Diastolic Casual readings tend to be those who reported that their mother encouraged disagreeng with her, who perceived their father as low in affection, who perceived their father as usually winning family arguments, who reported that their father spent little tıme with his children, and who recalled that their father made them feel resentment when he punished them The Father Irritability and Mother Affection variables act as suppressois in the cquation The variable, Demonstration of Affection, by Father does not contribute significantly to the $R$ even though it had a significant zero-order correlation with the dependent variable This combination of parent perception variables accounts for 28 per cent of the variance of Diastolic Casual Lability scores The $R$ is significant at the one per cent level

Other measures of blood pressure variability were used in this study Each involved blood pressure readings taken relatively independently We have already described Casual Variability The second measure is called Resting Variability This refers to the number of times that two of six consecutive readings differed by $10 \mathrm{~mm} / \mathrm{Hg}$ or more during the 20 min rest period in bed (see Procedures) The third index was called Home Variability and refers to the number of times across six readings taken by the subject at home that two consecutive readings differed by $10 \mathrm{~mm} \mathrm{Hg}$ or more [17] These three variability measures were not significantly correlated among themselves, in fact, the correlations were negligible for both systolic and diastolic measures, within and between measures The only significant correlation was between Systolıc and Didstolic Home Variability ( $r=036, p<001)$

In spite of the lack of relations among these three blood pressure indices, each of the measures seems related to psychological variables in a roughly consistent pattern Table 8 indicates that higher levels of variability are suggestively related to recall of a severe father and upward change in social class Negative properties of the 
relationship with the father are related to both systolic and diastolic measures of casual variability, and also systolic home variability

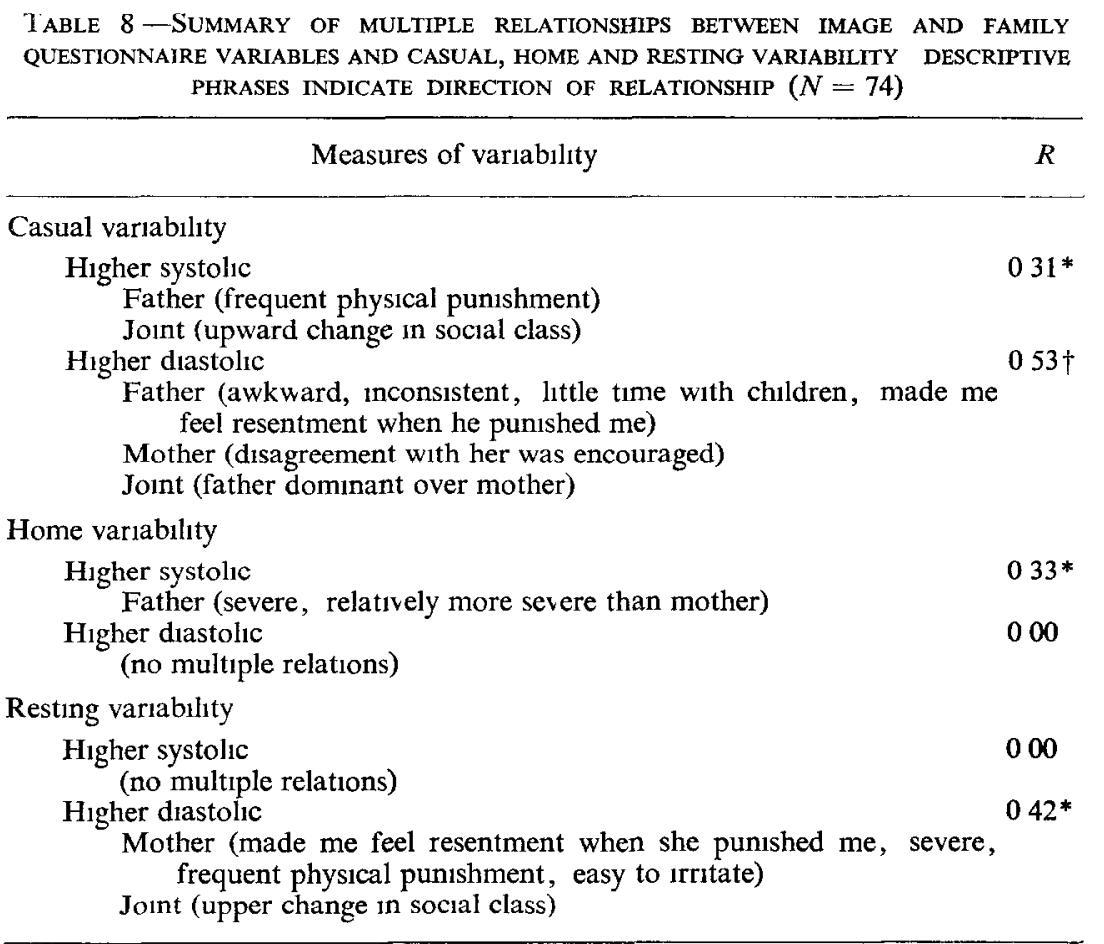

* $p$ less than 005

t $p$ less than 001

\section{DISCUSSION}

It is interesting to note that different properties of blood pressure appear related in this healthy college male group to different "parent images" Thus blood pressure levels show tendencies to be related to a positive rating of parents when iatrogenic effects were eliminated (Tables 5 and 6) Blood pressure vantabilty was associated with a negative father image, or a stern, dominant father, perhaps overly concerned with mobility (Table 8) Results reported elsewhere [16] reveal that reactin ity to cold pressor test was correlated highly in this same group with a negative image of the mother She was recalled as unjust and dominant over the father ( $R=053$, systolic), and as being stern and resented ( $R=049$, diastolic)

It is also pertinent that this study provides little if any support for the hypothesis that children with high blood pressure levels recall having "stressor parents" (punitive irritable, unloving etc ) The most that might be said is that the fathers of high blood pressure $S$ s are described as playing a role of mild authority The mother figure seems to be of little importance with regard to high or low blood pressure and if anything also has a "positive" image for these college males The results also failed to support the idea that high blood pressure $S$ s have upward mobile fathers and falled to show a relationship between dominance of either parent and level of blood pressure

These results are somewhat disturbing, given the widespread acceptance of thc 
original hypotheses, and the common use of the concept of the "prehypertensive" personality It should be noted that some of the studies which have shown a relationship between high blood pressure and personality [18] or between high blood pressure and later development of hypertension [19] have used as an index of the "prehypertensive" only a single high reading taken at earlier and later times This suggests that the single high readings obtained may have been equally a function of variable blood pressure as of a 'sustained' high level Variability of blood pressure, therefore, rather than only high blood pressure levels, may also be related to "neurotic" behavior in emotional situations This assumption was also partially examined by use of personality and behavioral tests given to these same subjects [20]

While the exact mechanısms whereby psychological stress or renal pathology is translated into increased arteriolar perıpheral constriction is as yet unknown, humoral substances, such as aldosterone and other steroids related to emotional behavior seem to be involved Hickam et al [21] using normal subjects, and Wolf et al [4] using hypertensive patients, have shown that noxious psychological stımuli is associated with vasoconstruction, reduced renal blood flow and increased filtration fraction and tachycardia Shapiro [22] reports studies done in the Soviet Union on monkeys in which permanent hypertension, with ECG and feudal changes, developed along with the production of experımental neuroses It would not seem unreasonable to assume that the physıological pathways from noxious psychological stimulı to emotional arousal to sustained pressure elevation might be traced in the future

The further question remains whether the parts of such pathways are subject to conditionıng in the early stages of the organism's development While many studies could be cited as suggestive support for this hypothesis, the reasoning would be speculative and familiar The problem of demonstrating early conditioning of neurophysiological processes in humans can be short circuited at this state of ignorance and approached psychologically by using the subjects' own reports of early parent treatment as the independent variable One of the few experiments using this approach (and which was repeated) related subjects' recall of parent treatment to physiological responses, was done by Funkenstein, Kıng and Drollette [23] Their data suggest that different patterns of authority, affection, and role model interact with the sex of the parent and the male offspring and are associated with blood pressure and heart rate changes under psychological stress The present study simply points to significant correlations between recalled properties of parent-child relationshıps and properties of blood pressure variability In both studies, white healthy college males were used as subjects In the present study, moreover, psychological factors were measured with a form easily taken by college men and women which shows promise of providing a reliable and stable research tool-the Parent Image Differentid This study, while drawing from such previous research, is largely exploratory and demands replication

\section{SUMMARY}

Using previous research as a basis it was hypothesized that $S$ s who report their parents as punitive, irritable and unloving have higher blood pressure than those who recall their patents in a more favorable light Further, it was hypothesized that subjects with upwardly mobile fathers, or with mothers dominant over $S s^{\prime}$ fathers, have higher blood pressure The $S$ s were 83 university males, paid volunteers Recall of parents was measured by a semantic differential and questionnaire Two casual 
readings at different times and places were averaged to produce an Average Casual blood pressure measure The mean of three readings taken after 20 min of bed rest and the median of six readings taken by $S$ in his living quarters were averaged to produce an index of Usual blood pressure Relationships between recall of parents and level of blood pressure were examined by simple and multiple correlations The data provided no support for the hypotheses and in some instances were contrary It was argued that variability and reactivity of blood pressure may be a more important variable than absolute level, and findings were then presented which lent support to this hypothesis

\section{REFERENCES}

1 McGinn N F, Harburg E, Julius S and McLeod J M Psychological correlates of blood pressure Psych Bull 61, 209 (1964)

2 Malmo R B Anxiety and behavioral arousal Psychol Rev 64, 286 (1957)

3 SAUL L A Hostility in cases of essential hypertension Psychosom Med 1, 153 (1939)

4 Wolf S, Pfeiffer J B , Ripley H S, Winter O S and WolfF H G Hypertension as a reaction pattern to stress Summary of experimental data on variations in blood pi essure and renal blood flow Ann Int Med 29, 1056 (1948)

5 Reiser M F, Rosenbaum M and Ferris E B Psychologic mechanisms in malignant hypertension Psychosom Med 13, 147 (1951)

6 HaRris R E Some observations on blood pressure in children 26th Report of the Ross Pediatric Research Conference 26, 49 (1958)

7 Silberstein F B and Seeman M Social mobility and prejudice Amer $J$ Sociology 65,258 (1959)

8 FARINA A Patterns of role dominance and conflict in parents of schizophrenic patients $J$ Abnorm Soc Psychol 61, 31 (1960)

9 Garmezy N, Clarke A P and Stockner Carol Child rearing attitudes of mothers and fathers as reported by schizophrenic and normal parents $J$ Abnorm Soc Psychol 63, 176 (1961)

10 THACKER E A A comparative study of normal and abnormal blood pressures among university students, including the cold pressor test Amer Heart $J$ 20,89 (1940)

11 Harburg $E$ Covert hostility Its social origins and relationship with overt complance Unpublished Ph D Thesis, University of Michigan (1962)

12 MCGinN N F Perception of parents and blood pressure Unpublished Ph D Thesis, University of Michigan (1962)

13 Osgood C E, Suci G and Tannenbaum P H The Measurement of Meaning University of Illınors Press, Urbana (1957)

14 Ginsburg G, McGinn N F and Harburg E The Parent Image Differential (1965) Typed report

15 KAISER H F Relatıng factors between studies based on different individuals Bureau of Educatıonal Research, University of Illınoıs, Urbana July 15 (1960) Mimeographed

16 MCGinN N F, HARBURG E and Julius S Blood pressure reactivity and recall of treatment by parents J Pers Soc Psychol 1, 147 (1965)

17 Julius S, McGinn N F, Harburg E and Hoobler S W Comparison of various clinical measurements of blood pressure with the self-determination technique in normotensive college males I Chron Dis 17, 391 (1964)

18 Kalis B $L$, Harris $R$ E, Sokolow $M$ and Carpenter $L G, J R$ Response to psychological stress in patients with essential hypertension Amer Heart $J$ 53, 572 (1957)

19 Levy R L, Hillman C C, Stroud W D and White P D Transient hypertension its sigmificance in terms of later development of sustained hypertension and cardiovascular-renal diseases $J A M A$ 126, 829 (1944)

20 Harburg E, Julius S, MCGinn N F, McLeod J and Hoobler S W Personality traits and behavioral patterns associated with systolic blood pressure levels in college males $J$ Chron Dis 17, 405 (1964)

21 Hickam J B, Cargell W H and Golden A Cardiovascular reactions to emotional stımulı Effect on cardiac output, ateriovenous oxygen difference, arterial pressure, and peripheral resistance J Clin Investigation 27, 290 (1948)

22 Shapiro A P Psychophysiologic mechanisms in hypertensive vascular disease Ann Int Med 53, $64(1960)$

23 Funkenstein D, King S H and Drolette M Mastery of Stiess Harvard University Press, Cambridge (1957) 